INOVAÇÃO/NANOTECNOLOGIA

\section{Bayer fecha fábrica de nanotubos de carbono}

Depois de apenas 4 anos, a indústria farmacêutica Bayer resolveu fechar as portas da uma das maiores fábricas de nanotubos de carbono do mundo. Em um comunicado à imprensa, Patrick Thomas, CEO da Bayer MaterialScience, explicou que a empresa percebeu que as áreas potenciais de aplicação dos nanotubos, que antes pareciam promissoras, "têm se fragmentado ou têm pouco a ver com os principais produtos da empresa e seu espectro de aplicação".

A Bayer havia inaugurado sua fábrica no início de 2009, em Leverkusen, Alemanha, com investimentos de cerca de 22 milhôes de euros, aproximadamente $\mathrm{R} \$ 61$ milhôes. O objetivo era desenvolver novas tecnologias e aplicações com base no grande potencial dos nanotubos de carbono.

Trata-se de estruturas tubulares com dimensões de cerca de um bilionésimo de metro $\left(10^{-9} \mathrm{~m}\right)$ que produzem propriedades elétricas, mecânicas, ópticas e químicas que podem beneficiar produtos esportivos, como raquetes e bicicletas, tornando-os mais resistentes; aumentar a mobilidade com a redução do peso de veículos; e possibilitar o desenvolvimento de produtos eletrônicos como televisores de tela plana.

À epoca, a Bayer recebeu cerca de 40 milhões de euros do Ministério da Educação e Pesquisa da Alemanha, para o período de quatro anos. "Esta aliança irá desempenhar um papel significativo na implementação da estratégia de alta tecnologia do governo federal, por meio da qual pretendemos reforçar a competitividade da Alemanha”, afirmou Thomas Rachel, secretário de Estado Parlamentar do Ministério Federal da Alemanha para Educação e Pesquisa (BMBF), durante a inauguração da planta de nanotubos de carbono.

Apesar de a fábrica ter encerrado suas atividades, Stefan Paul Mechnig, porta-voz de Bayer MaterialScience esclareceu que a Bayer pretende continuar contribuindo para a área, por meio da transmissão de tecnologia e distribuição de informação para pequenas e médias empresas. "Queremos continuar trabalhando profundamente com o desenvolvimento e os nossos parceiros de negócios para encontrar o melhor uso possível e posterior utilização do nosso portfólio de nanotubos de carbono, em particular, para conhecimentos adquiridos e patentes". Segundo Mechnig, apesar do fechamento da fábrica, a empresa ainda acredita no grande potencial da nanotecnologia e dos nanotubos de carbono e, portanto, assume que a investigação e o desenvolvimento nessa área vão continuar.

No ramo de produção de nanotubos de carbono estão grandes empresas como a chinesa CNano, com uma linha de produção com capacidade de produção de 500 toneladas ao ano, e a belga Nanocyl, considerada a atual líder mundial na fabricação dessas estruturas. Que os investimentos permaneçam no setor.

Marcela Salazar Granada

\section{EVENTOS CIENTÍFICOS}

Nanotecnologias em debate internacional
A multiplicidade de eventos científicos sobre nanotecnologias que ocorrerão no segundo semestre deste ano reflete a riqueza e o dinamismo da área. A partir de agosto ocorrerão encontros na Alemanha, Canadá, China, Coreia do Sul, Emirados Árabes, Espanha, Estados Unidos, Índia, IrNa, Israel, Japão e Singapura. Segue abaixo alguns desses eventos:

\section{AGOSTO}

- 4th ICNFA2013 - International Conference on Nanotechnology. Em Toronto, Canadá.

13th IEEE - International Conference on Nanotechnology. Em Beijing, China.

- NanoScience + Engineering 2013. Em San Diego, Estados Unidos.

\section{SETEMBRO}

- International Conference on Computational Modelling of Nanostructured Materials. Em Frankfurt, Alemanha.

14th edition of the Trends in Nanotechnology International Conference (TNT 2013). Em Sevilha, Espanha.

\section{OUTUBRO}

- 2nd International Conference on Nanostructures, Nanomaterials and Nanoengineering (ICNNN 2013), Coreia do Sul - International Nanotechnology Conference 2013. Em Dubai, Emirados Árabes.

\section{NOVEMBRO}

4th International Conference on Ultrafine Grained and Nanostructured Materials.

TEm eerã, Irã.

- Nanowires 2013. Em Rehovot, Israel. DEZEMBRO

- 3rd Nano Today Conference. Em Singapura. 